\title{
Preparation, sintering, and ferroelectric properties of layer- structured strontium bismuth titanium oxide ceramics
}

\author{
Chung-Hsin Lu*, Chung-Han $\mathrm{Wu}$ \\ Department of Chemical Engineering, National Taiwan University, Taipei, Taiwan, ROC
}

Received 11 January 2001; received in revised form 22 May 2001; accepted 29 May 2001

\begin{abstract}
The preparation and ferroelectric properties of layer-structured $\mathrm{SrBi}_{4} \mathrm{Ti}_{4} \mathrm{O}_{15}$ ceramics were investigated in this study. During the solid-state reaction, the formation of $\mathrm{SrBi}_{4} \mathrm{Ti}_{4} \mathrm{O}_{15}$ started at $700{ }^{\circ} \mathrm{C}$, and the pure layered structure was completely formed at $900{ }^{\circ} \mathrm{C}$. The obtained $\mathrm{SrBi}_{4} \mathrm{Ti}_{4} \mathrm{O}_{15}$ powder was found to be hardly sintered at low temperatures. Raising the sintering temperature higher than $1100{ }^{\circ} \mathrm{C}$ led to an increase in the density of $\mathrm{SrBi}_{4} \mathrm{Ti}_{4} \mathrm{O}_{15}$ ceramics; however, a secondary phase having a pyrochlore structure was also produced on the surface of the ceramics due to the thermal decomposition reaction. This thermal decomposition was caused by the vaporization of bismuth species outward from the $\mathrm{SrBi}_{4} \mathrm{Ti}_{4} \mathrm{O}_{15}$ ceramics at elevated temperatures. In order to suppress the decomposition reaction, a process of covering $\mathrm{SrBi}_{4} \mathrm{Ti}_{4} \mathrm{O}_{15}$ compacts on the sintered ceramics was developed. This process successfully resulted in highly densified $\mathrm{SrBi}_{4} \mathrm{Ti}_{4} \mathrm{O}_{15}$ ceramics having the pure layer-structured phase. These well-sintered $\mathrm{SrBi}_{4} \mathrm{Ti}_{4} \mathrm{O}_{15}$ ceramics exhibited good ferroelectric properties with high remnant polarization $\left(2 P_{\mathrm{r}}=13.52 \mu \mathrm{C} / \mathrm{cm}^{2}\right)$ and low coercive field $\left(2 E_{\mathrm{c}}=52.31 \mathrm{kV} / \mathrm{cm}\right)$. (C) 2002 Published by Elsevier Science Ltd.
\end{abstract}

Keywords: Ferroelectric properties; Phase composition; Reaction; Sintering; $\mathrm{SrBi}_{4} \mathrm{Ti}_{4} \mathrm{O}_{15}$

\section{Introduction}

Recently the families of ferroelectrics receive great attention for their use in the nonvolatile ferroelectric random access memory (FeRAM). ${ }^{1}$ Among these ferroelectrics, perovskite $\mathrm{Pb}(\mathrm{Zr}, \mathrm{Ti}) \mathrm{O}_{3}$ (PZT) had been extensively investigated for the characteristics of large remnant polarization $\left(P_{\mathrm{r}}\right)$, moderately low coercive field $\left(E_{\mathrm{c}}\right)$, and high Curie temperature. ${ }^{2,3}$ However, there is a serious polarization fatigue problem when using platinum as the electrodes of PZT thin films. ${ }^{4,5}$ The other class of ferroelectric materials of recent interest is the bismuth layer-perovskite ferroelectrics. ${ }^{6}$ This type of material exhibits good ferroelectric properties including moderate remnant polarization, low coercive field, long retention, and low tendency to imprint. Most important of all, layer-perovskite materials exhibit excellent fatigue endurance in comparison with PZT and its family. 7,8

The layer-perovskite materials described by Aurivillius are named after him as Aurivillius compounds. ${ }^{9-11}$ The

* Corresponding author. Tel.: +886-2-3635230; fax: +886-23623040 .

E-mail address: chlu@ccms.ntu.edu.tw (C.-H. Lu). chemical formula of Aurivillius compounds is $\left(\mathrm{Bi}_{2} \mathrm{O}_{2}\right)^{2+}\left(\mathrm{A}_{x-1} \mathrm{~B}_{x} \mathrm{O}_{3 x+1}\right)^{2-}$, where $\mathrm{A}$ represents the 12fold coordinated cation with low valences in the perovskite sublattice; B denotes the octahedral site with high valences; $x$ is the number of octahedral layers in the perovskite block between the rock-salt type $\left(\mathrm{Bi}_{2} \mathrm{O}_{2}\right)^{2+}$ layers along the $c$ axis. Strontium bismuth titanate is one of the family of layer-perovskite ferroelectrics $\left(\mathrm{SrBi}_{4} \mathrm{Ti}_{4} \mathrm{O}_{15}, x=4\right)$. The $\mathrm{SrBi}_{4} \mathrm{Ti}_{4} \mathrm{O}_{15}$ thin films are demonstrated to possess promising ferroelectric properties and low fatigue of the remnant polarization after $10^{10}$ cycling with platinum electrodes. ${ }^{12}$ In order to apply ferroelectric materials to IC industry, several processes have been adopted for depositing ferroelectric thin films. In physical vapor deposition (PVD) processes, such as radio-frequency (rf) sputtering and laser deposition, the preparation of dense ceramic targets is an important issue. However, the sinterability and the behavior of $\mathrm{SrBi}_{4} \mathrm{Ti}_{4} \mathrm{O}_{15}$ ceramics under high temperatures have not been investigated in detail. In this study, the reaction mechanism of $\mathrm{SrBi}_{4} \mathrm{Ti}_{4} \mathrm{O}_{15}$ in the solid-state reaction was examined for synthesizing the pure compound. The sintering behavior and the microstructural development of $\mathrm{SrBi}_{4} \mathrm{Ti}_{4} \mathrm{O}_{15}$ in three different sintering 
processes were studied. The ferroelectric properties of the obtained $\mathrm{SrBi}_{4} \mathrm{Ti}_{4} \mathrm{O}_{15}$ ceramics were also investigated.

\section{Experimental}

The starting materials included high-purity $\mathrm{SrCO}_{3}$ (Aldrich, 99\% pure), $\mathrm{Bi}_{2} \mathrm{O}_{3}$ (Aldrich, 99.9\% pure), and $\mathrm{TiO}_{2}$ (Aldrich, $>99 \%$ pure). These materials were weighed according to the stoichiometric composition of $\mathrm{SrBi}_{4} \mathrm{Ti}_{4} \mathrm{O}_{15}$, followed by ball-milling in ethanol for 48 $\mathrm{h}$, using zirconia balls in a polyethylene jar. After milling, the slurry was dried in a rotary evaporator under a reduced pressure. Thermogravimetric analysis (TGA) and differential scanning calorimetry (DSC) were performed to investigate the thermal behavior of the dried mixtures. The dried powder was heated in air from 500 to $1000{ }^{\circ} \mathrm{C}$ without soaking and then quenched to room temperature. The other $2 \mathrm{~h}$-calcination was also performed from 800 to $1200{ }^{\circ} \mathrm{C}$. The phases present in the quenched and calcined samples were identified by X-ray powder diffraction (XRD) analysis using $\mathrm{Cu} K_{\alpha}$ radiation. The calcined powder was first treated by ultrasonic vibration using ethyl alcohol as a dispersion agent, and then a laser diffraction method was performed to measure the particle size.

PVA (3 wt. \%) was added to the obtained $\mathrm{SrBi}_{4} \mathrm{Ti}_{4} \mathrm{O}_{15}$ powder to study the sintering behavior. The powder mixtures were pressed into disks under a pressure of about $200 \mathrm{MPa}$ and sintered by three different processes at $1000-1200{ }^{\circ} \mathrm{C}$ for $2 \mathrm{~h}$. The schematic diagrams of these three processes are shown in Fig. 1. Process I was to sinter the pellets without any covering in air. In process II, a powder-bed consisting of $\mathrm{SrBi}_{4} \mathrm{Ti}_{4} \mathrm{O}_{15}$ powder was employed to cover the pressed pellets during sintering. In process III, monophasic $\mathrm{SrBi}_{4} \mathrm{Ti}_{4} \mathrm{O}_{15}$ powder was first pressed at $30 \mathrm{MPa}$, then laminated on the pressed pellets containing the calcined powder, and the sintering process was performed in the powder bed as described in process II.

The phase variation and composition of the sintered ceramic surface were analyzed by XRD and energy dispersive X-ray spectroscopy (EDS), respectively. The microstructure of the sintered ceramics was observed by a scanning electron microscope (SEM). To measure the ferroelectric properties, silver paste was painted on the surface of the sintered $\mathrm{SrBi}_{4} \mathrm{Ti}_{4} \mathrm{O}_{15}$ ceramics and heated at $500{ }^{\circ} \mathrm{C}$. The hysteresis behavior was analyzed by a Sawyer-Tower circuit and recorded on a digital oscilloscope.

\section{Results and discussion}

\subsection{Formation of $\mathrm{SrBi}_{4} \mathrm{Ti}_{4} \mathrm{O}_{15}$ in the solid-state reaction}

The starting materials of $\mathrm{SrBi}_{4} \mathrm{Ti}_{4} \mathrm{O}_{15}$ were heated with a heating rate of $10{ }^{\circ} \mathrm{C} / \mathrm{min}$ at elevated temperatures and quenched to room temperature. Fig. 2 shows the XRD patterns of the quenched specimens, and the variation of the relative intensity of each phase is illustrated in Fig. 3 based on the results of Fig. 2. The relative intensity of each compound was calculated from the ratio of the intensity of the specific diffraction peak of each compound to the sum of the intensity of the specific diffraction peak of all compounds. A small amount of $\mathrm{Bi}_{2} \mathrm{O}_{3}$ and an unidentified compound were present at $400{ }^{\circ} \mathrm{C} . \mathrm{Bi}_{12} \mathrm{TiO}_{20}$ was formed and the amount of unidentified phase was reduced at $500{ }^{\circ} \mathrm{C}$. At $600{ }^{\circ} \mathrm{C}$, another intermediate phase- $\mathrm{Bi}_{4} \mathrm{Ti}_{3} \mathrm{O}_{12}$ was also produced. When the temperature was raised to $700{ }^{\circ} \mathrm{C}$, $\mathrm{SrBi}_{4} \mathrm{Ti}_{4} \mathrm{O}_{15}$ started to form with the presence of a minor amount of $\mathrm{SrTiO}_{3}$ and residual $\mathrm{Bi}_{12} \mathrm{TiO}_{20}$. The amount of $\mathrm{SrBi}_{4} \mathrm{Ti}_{4} \mathrm{O}_{15}$ increased rapidly with a rise in heating temperatures. The single phase $\mathrm{SrBi}_{4} \mathrm{Ti}_{4} \mathrm{O}_{15}$ was obtained at $1000{ }^{\circ} \mathrm{C}$ as all $\mathrm{SrTiO}_{3}$ disappeared.

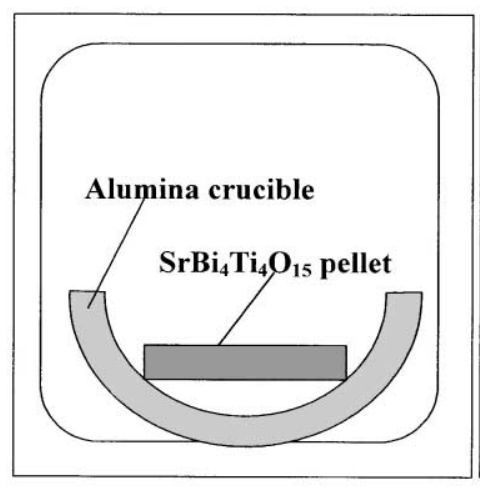

Process I

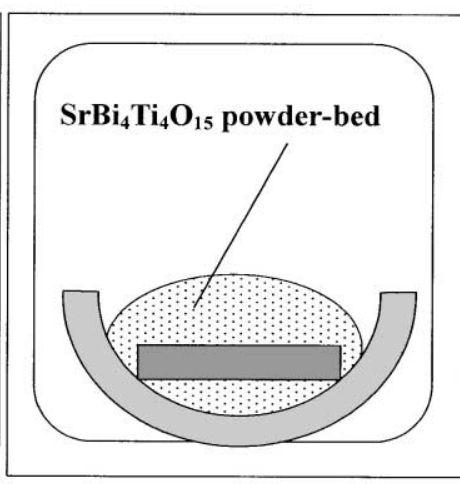

Process II

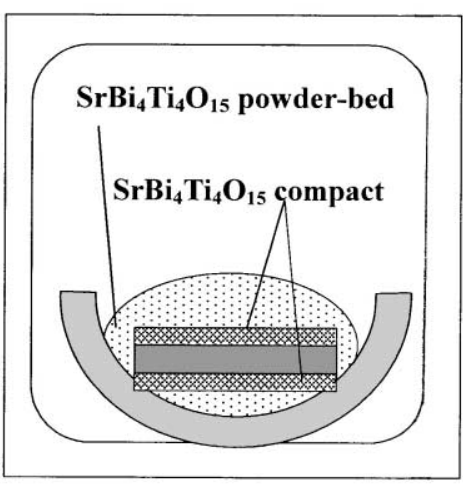

Process III

Fig. 1. Schematic diagrams for three kinds of sintering processes. 


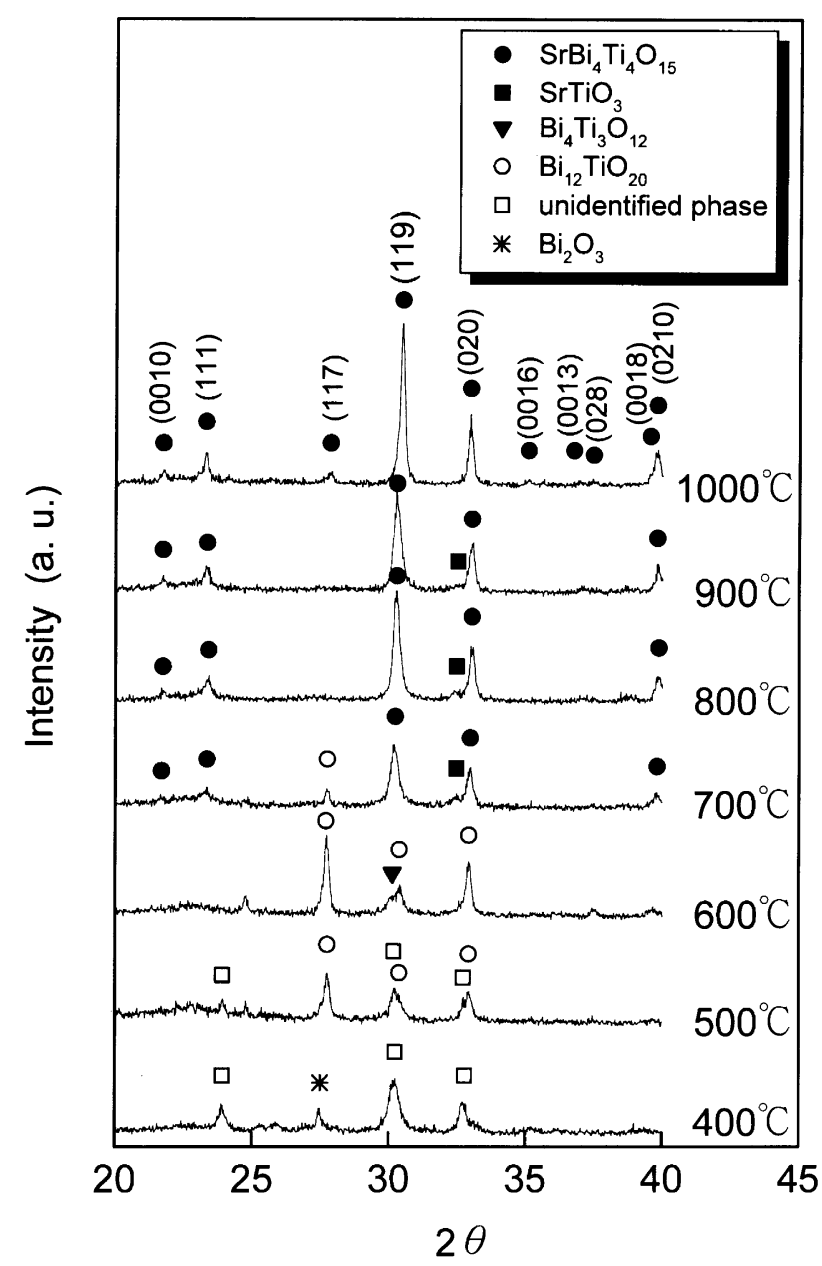

Fig. 2. X-ray diffraction patterns of the starting materials of $\mathrm{SrBi}_{4} \mathrm{Ti}_{4} \mathrm{O}_{15}$ quenched at various temperatures.

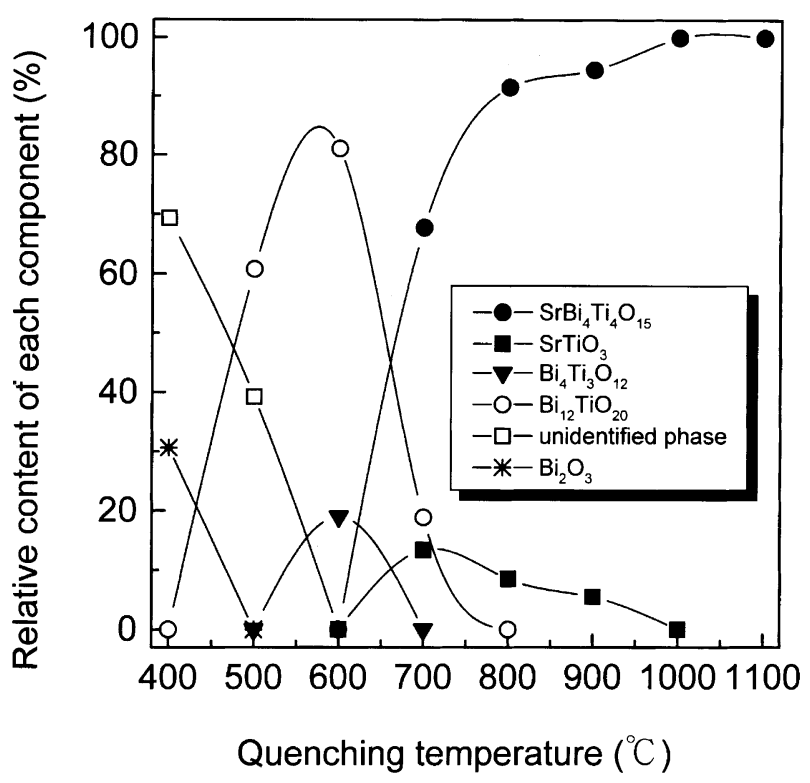

Fig. 3. Relative intensity of resultant phases in the starting materials of $\mathrm{SrBi}_{4} \mathrm{Ti}_{4} \mathrm{O}_{15}$ quenched at various temperatures.
In the DSC/TGA thermal analysis, a significant weight loss of the starting materials was detected at temperatures ranging from 500 to $600{ }^{\circ} \mathrm{C}$, and an endothermic peak was observed in the same temperature range in DSC. This weight loss was ascribed to the release of carbon dioxide from $\mathrm{SrCO}_{3}$ in the starting materials. There was another sharp exotherm detected just below $700{ }^{\circ} \mathrm{C}$ in DSC. The exothermal reaction was deduced to be the formation of $\mathrm{SrBi}_{4} \mathrm{Ti}_{4} \mathrm{O}_{15}$. From the XRD analysis, the formation of $\mathrm{SrBi}_{4} \mathrm{Ti}_{4} \mathrm{O}_{15}$ can be expressed by the following equation:

$\mathrm{Bi}_{4} \mathrm{Ti}_{3} \mathrm{O}_{12}+\mathrm{SrTiO}_{3} \rightarrow \mathrm{SrBi}_{4} \mathrm{TiO}_{15}$

In order to lower the temperature for synthesizing $\mathrm{SrBi}_{4} \mathrm{Ti}_{4} \mathrm{O}_{15}$, the starting materials were calcined at various temperatures for $2 \mathrm{~h}$. It was found that $\mathrm{SrTiO}_{3}$ still existed in the sample after calcination at $800{ }^{\circ} \mathrm{C}$. Once the calcination temperature reached $900{ }^{\circ} \mathrm{C}$, the single phase $\mathrm{SrBi}_{4} \mathrm{Ti}_{4} \mathrm{O}_{15}$ was obtained. The XRD pattern of synthesized $\mathrm{SrBi}_{4} \mathrm{Ti}_{4} \mathrm{O}_{15}$ is consistent with that reported in literature. ${ }^{13}$ The phase of $\mathrm{SrBi}_{4} \mathrm{Ti}_{4} \mathrm{O}_{15}$ had no change between 1000 and $1100{ }^{\circ} \mathrm{C}$. According to the particle size analysis, the $900{ }^{\circ} \mathrm{C}$-calcined powder had a narrow size distribution, with the average particle size around $2.2 \mu \mathrm{m}$.

\subsection{Sintering of $\mathrm{SrBi}_{4} \mathrm{Ti}_{4} \mathrm{O}_{15}$ ceramics}

The obtained $\mathrm{SrBi}_{4} \mathrm{Ti}_{4} \mathrm{O}_{15}$ powder was pressed and sintered at various temperatures for $2 \mathrm{~h}$ by using process I. As shown in Fig. 4, after sintering at $1050{ }^{\circ} \mathrm{C}$, the density of the sintered ceramics remained nearly unchanged just like the green density of the compacts. Sintering at higher temperatures led to an increase in

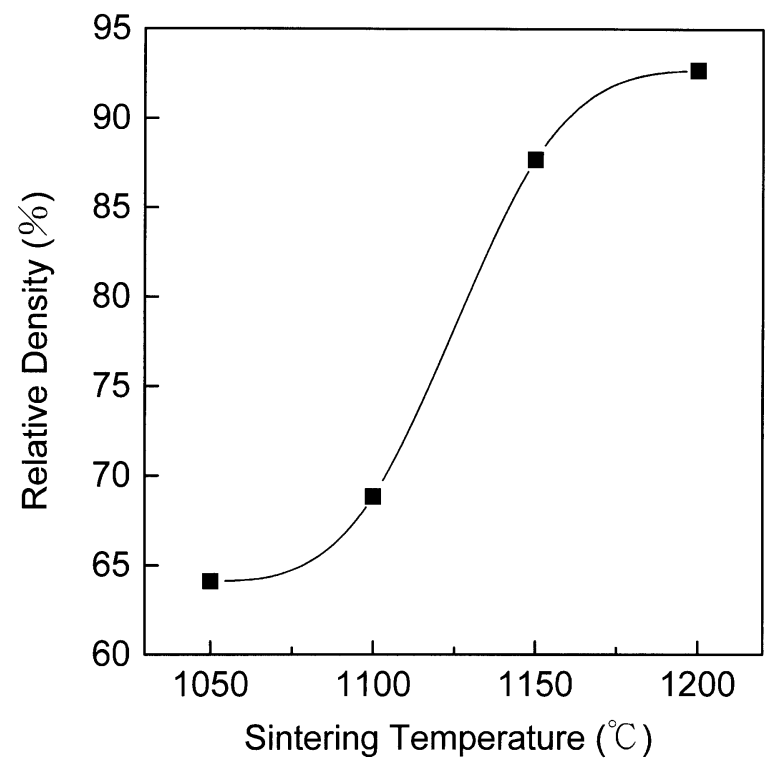

Fig. 4. Density of $\mathrm{SrBi}_{4} \mathrm{Ti}_{4} \mathrm{O}_{15}$ ceramics sintered in process I. 
density. The density of the $1200{ }^{\circ} \mathrm{C}$-sintered pellets reached a maximum of $92.7 \%$ relative density (the theoretic density of $\mathrm{SrBi}_{4} \mathrm{Ti}_{4} \mathrm{O}_{15}=7.448 \mathrm{~g} / \mathrm{cm}^{3}$ ). Nevertheless, there existed a large amount of glassy scraps on the surface of this specimen, and a weight loss around $1.5 \mathrm{wt} . \%$ was found. The surfaces of the sintered pellets were examined by XRD. Fig. 5 indicates that after $1050{ }^{\circ} \mathrm{C}$-sintering, only $\mathrm{SrBi}_{4} \mathrm{Ti}_{4} \mathrm{O}_{15}$ existed in the sample. However, at temperature higher than $1100{ }^{\circ} \mathrm{C}$, a secondary phase was observed. The amount of $\mathrm{SrBi}_{4} \mathrm{Ti}_{4} \mathrm{O}_{15}$ gradually decreased with increasing temperature. The secondary phase became the major compound when the sintering temperature reached $1200{ }^{\circ} \mathrm{C}$. The above phenomena are attributed to high-temperature decomposition reaction. The powder ground from the $1200{ }^{\circ} \mathrm{C}$-sintered sample was also examined by XRD and only a small amount of secondary phase was detected. According to the XRD pattern, the secondary phase formed on the surface of decomposed samples was found to have a crystal structure of pyrochlore phase. This pyrochlore phase was also observed by Nibou et al. when they prepared $\mathrm{SrBi}_{4} \mathrm{Ti}_{4} \mathrm{O}_{15}$ thin films. ${ }^{14}$ The microstructure of decomposed $\mathrm{SrBi}_{4} \mathrm{Ti}_{4} \mathrm{O}_{15}$ ceramics is shown in Fig. 6. The pyrochlore phase possessed a plate-like morphology with an exceptionally large dimension greater than $10 \mu \mathrm{m}$.

The composition of the surface of sintered pellets was analyzed by the energy dispersive X-ray spectroscopy (EDS). The surface composition of the ceramics sintered at $1050{ }^{\circ} \mathrm{C}$ was very close to stoichiometry. However, for the $1200{ }^{\circ} \mathrm{C}$-sintered samples, the compositional ratio of $\mathrm{Sr}$ : Bi: Ti was 1: 1.2: 4.1. This indicates that the

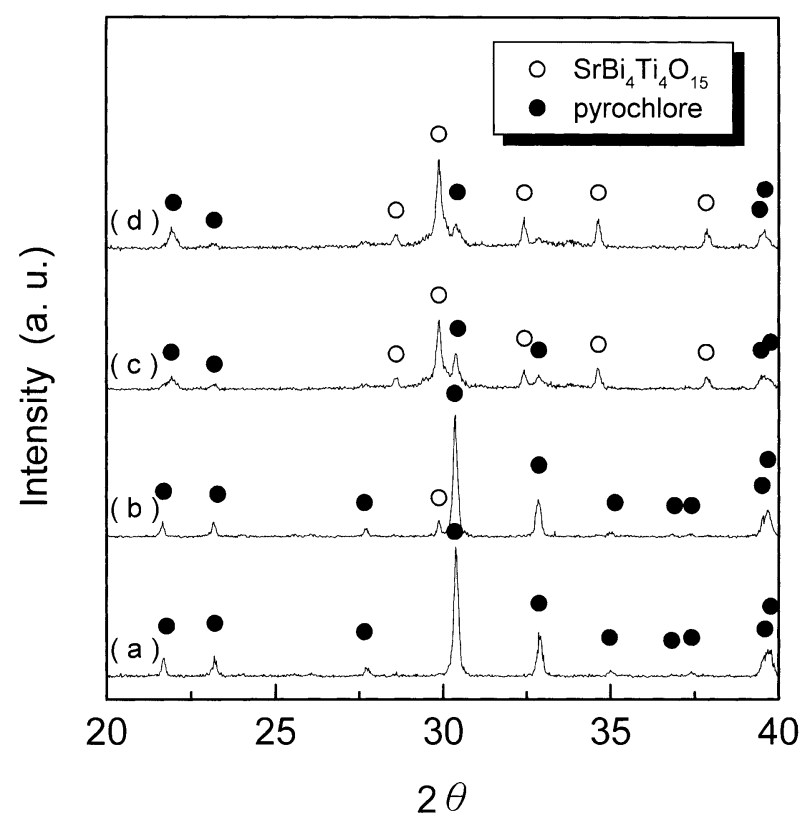

Fig. 5. X-ray diffraction patterns for the surface of $\mathrm{SrBi}_{4} \mathrm{Ti}_{4} \mathrm{O}_{15}$ ceramics sintered at (a) $1050{ }^{\circ} \mathrm{C}$, (b) $1100{ }^{\circ} \mathrm{C}$, (c) $1150{ }^{\circ} \mathrm{C}$, and (d) $1200^{\circ} \mathrm{C}$ for $2 \mathrm{~h}$. amount of bismuth species had a $70 \mathrm{~mol} \%$ reduction while other components remained almost unchanged. According to the EDS analysis, decomposition reaction was due to the volatilization of bismuth species at elevated temperatures. Similar deficiency behavior of bismuth species was also found during the sintering of another bismuth-layered compound- $\mathrm{SrBi}_{2} \mathrm{Ta}_{2} \mathrm{O}_{9} .{ }^{15}$

The $1150{ }^{\circ} \mathrm{C}$-sintered samples were polished at various depths from the surface and examined by XRD. Fig. 7 indicates that as the depth from the surface

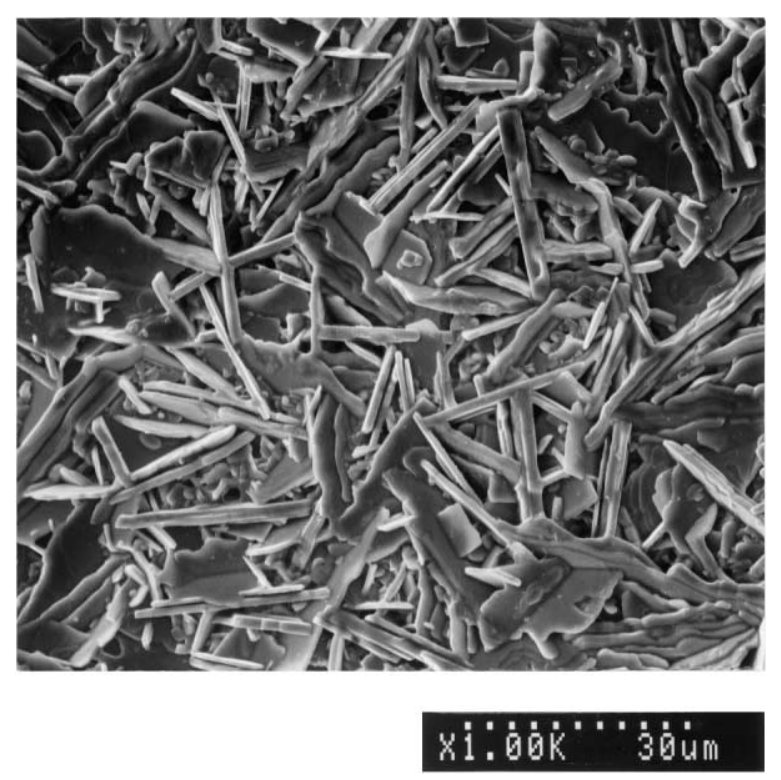

Fig. 6. Scanning electron micrograph of the $\mathrm{SrBi}_{4} \mathrm{Ti}_{4} \mathrm{O}_{15}$ ceramics sintered at $1200{ }^{\circ} \mathrm{C}$ in process I.

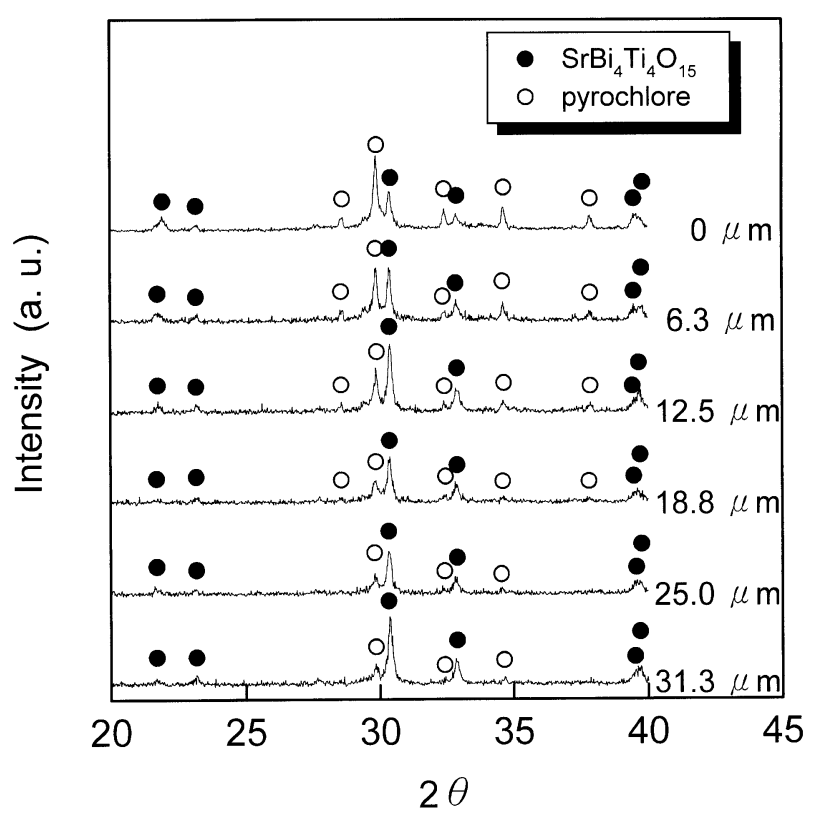

Fig. 7. X-ray diffraction patterns of the $1150{ }^{\circ} \mathrm{C}$-sintered $\mathrm{SrBi}_{4} \mathrm{Ti}_{4} \mathrm{O}_{15}$ ceramics at various depth from sample surface. 
increased, the intensity of pyrochlore phase gradually decreased while $\mathrm{SrBi}_{4} \mathrm{Ti}_{4} \mathrm{O}_{15}$ became the major phase. The amount of pyrochlore phase present in the ceramics was semi-quantified by calculating the ratio of pyrochlore intensity to the sum of the intensity of pyrochlore (py) and $\mathrm{SrBi}_{4} \mathrm{Ti}_{4} \mathrm{O}_{15}(\mathrm{SBTi})\left[\mathrm{I}_{\mathrm{py}(444)} /\left(\mathrm{I}_{\mathrm{py}(444)}+\mathrm{I}_{\mathrm{SBTi}(119))}\right)\right.$. Fig. 8 illustrates the relationship between the quantity of pyrochlore phase and the distance from bulk surface. The amount of pyrochlore phase decreased steeply near the pellet surface while the tendency of reduction became moderate as the depth of ceramic increased to $20 \mu \mathrm{m}$. It was found from this diagram that the decomposition reaction also extended to the interior part of the pellets with considerable depth. Since the thermal decomposition was attributed to the vaporization of bismuth species from the surface, the formation of pyrochlore phase inside the samples is considered to result from the diffusion of bismuth species from interior to the surface, and the concentration gradient of bismuth species was attributed to the driving force of diffusion.

\subsection{Modified sintering processes of $\mathrm{SrBi}_{4} \mathrm{Ti}_{4} \mathrm{O}_{15}$ ceramics}

Since the sintering of $\mathrm{SrBi}_{4} \mathrm{Ti}_{4} \mathrm{O}_{15}$ is accompanied with thermal decomposition at high temperatures, suppressing the formation of pyrochlore phase is necessary for producing high quality ferroelectric ceramics. The results in Section 3.2 indicate that the decomposition reaction started from the surface of ceramics; therefore, process II that heated $\mathrm{SrBi}_{4} \mathrm{Ti}_{4} \mathrm{O}_{15}$ compacts in a powder-bed was designed to prevent the exposure of bulk surface to air. The obtained pure-phase $\mathrm{SrBi}_{4} \mathrm{Ti}_{4} \mathrm{O}_{15}$

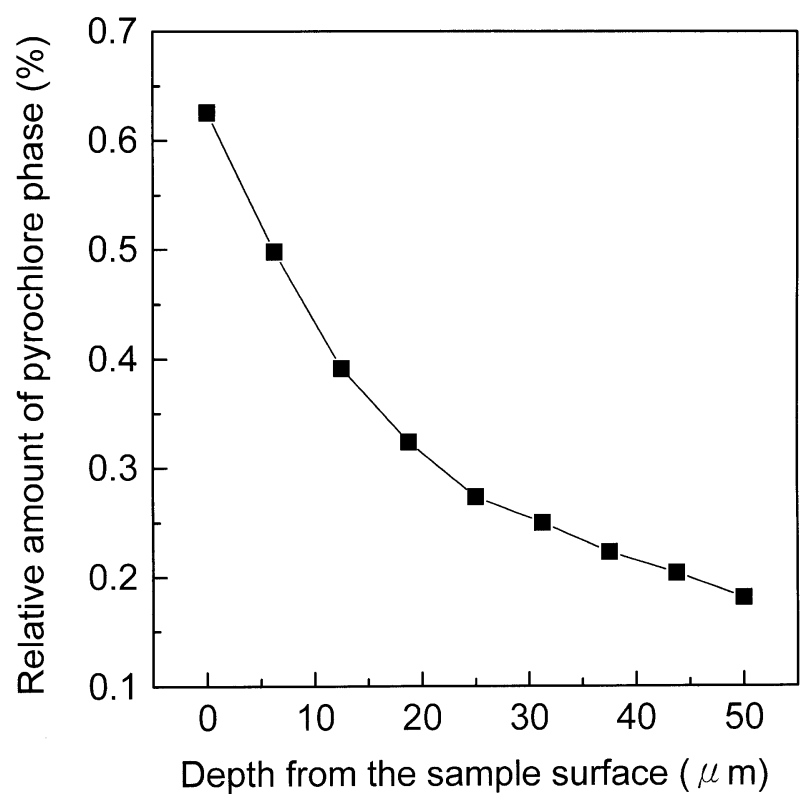

Fig. 8. The relationship between the relative amount of pyrochlore and the depth from the sample surface. powder was used in this process. Fig. 9 reveals the sintering behavior of $\mathrm{SrBi}_{4} \mathrm{Ti}_{4} \mathrm{O}_{15}$ ceramics in process II. The density of the ceramics was elevated to $96 \%$ of the theoretical density after sintering at $1200{ }^{\circ} \mathrm{C}$. The XRD pattern of the surface of the sintered pellets in process II is shown in Fig. 10. Although the major phase of the ceramic surface was perovskite $\mathrm{SrBi}_{4} \mathrm{Ti}_{4} \mathrm{O}_{15}$, a small amount of pyrochlore phase was also formed on the

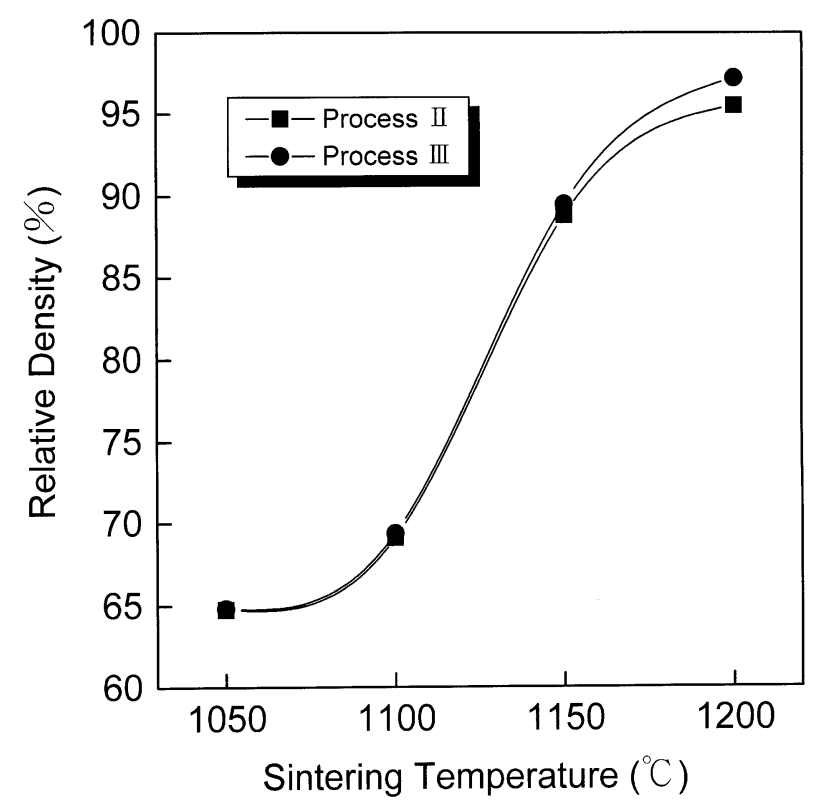

Fig. 9. Density of $\mathrm{SrBi}_{4} \mathrm{Ti}_{4} \mathrm{O}_{15}$ ceramics sintered in process II and process III.

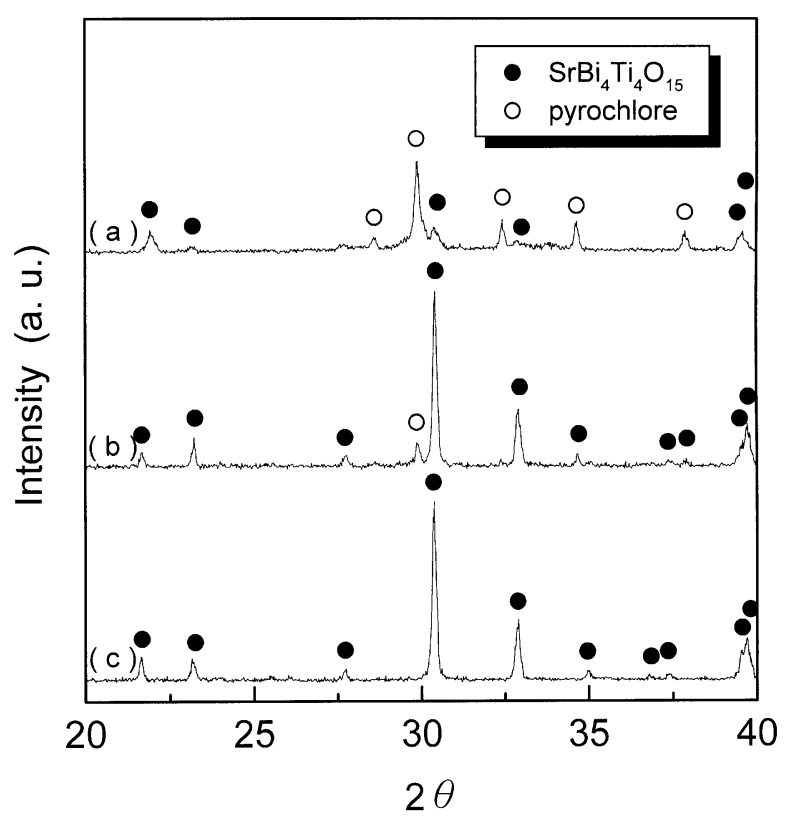

Fig. 10. X-ray diffraction patterns of the surface of $\mathrm{SrBi}_{4} \mathrm{Ti}_{4} \mathrm{O}_{15}$ ceramics sintered in (a) process I, (b) process II, and (c) process III at $1200{ }^{\circ} \mathrm{C}$. 
surface of the pellets. This result indicates that the decomposition reaction cannot be completely inhibited by the powder bed process.

For obtaining pure-phase and well-sintered $\mathrm{SrBi}_{4} \mathrm{Ti}_{4} \mathrm{O}_{15}$ ceramics, a pellet-laminated process (process III) was designed to suppress the diffusion of bismuth species by laminating other ceramic compacts. In order to avoid unnecessary reaction at high temperatures, the pellets adopted in this process were the compacts that pressed slightly from monophasic $\mathrm{SrBi}_{4} \mathrm{Ti}_{4} \mathrm{O}_{15}$ powder. As shown in Fig. 9, the density of ceramics reached a maximum of about $97.2 \%$ relative density after sintering at $1200{ }^{\circ} \mathrm{C}$. Not only the dense ceramics were obtained, this process also produced pure $\mathrm{SrBi}_{4} \mathrm{Ti}_{4} \mathrm{O}_{15}$ ceramics without decomposition as shown in Fig. 10(c). Fig. 11 shows the micrographs of $\mathrm{SrBi}_{4} \mathrm{Ti}_{4} \mathrm{O}_{15}$ ceramics obtained by process III. The microstructure of $1100{ }^{\circ} \mathrm{C}$ sintered $\mathrm{SrBi}_{4} \mathrm{Ti}_{4} \mathrm{O}_{15}$ was very porous, fine grains with grain size around $0.1-0.8 \mu \mathrm{m}$ were observed in the specimen [shown in Fig. 11(a)]. Apparent grain growth occurred as the sintering temperature raising to $1150{ }^{\circ} \mathrm{C}$ [Fig. 11(b)]. Although the structure became denser with the growing grains, a number of voids still existed in the specimen. As shown in Fig. 11(c), raising the sintering temperature to $1200{ }^{\circ} \mathrm{C}$ significantly reduced the number of pores and densified the $\mathrm{SrBi}_{4} \mathrm{Ti}_{4} \mathrm{O}_{15}$ ceramics. The grains were further coarsened to $1.4-1.7 \mu \mathrm{m}$. The variation of microstructures confirms the results of sintering density obtained previously.

\subsection{Ferroelectric properties of $\mathrm{SrBi}_{4} \mathrm{Ti}_{4} \mathrm{O}_{15}$ ceramics}

The electric properties of the $1200{ }^{\circ} \mathrm{C}$-sintered samples prepared by three different sintering processes were measured. For the sample obtained by process I, no hysteresis behavior was detected because of the occurrence of a serious leakage. From the microstructure observed previously, the large leakage current is attributed to the insufficient connection of the interface between ceramics and silver electrodes. The ferroelectric properties of the $1200{ }^{\circ} \mathrm{C}$-sintered $\mathrm{SrBi}_{4} \mathrm{Ti}_{4} \mathrm{O}_{15}$ obtained by the powder bed process (process II) are shown in Fig. 12(a). A well-developed P-E loop was obtained, and the remnant polarization $\left(2 P_{\mathrm{r}}\right)$ and coercive field $\left(2 E_{\mathrm{c}}\right)$ were $12.4 \mu \mathrm{C} / \mathrm{cm}^{2}$ and $82.2 \mathrm{kV} / \mathrm{cm}$, respectively. The decomposition-free $\mathrm{SrBi}_{4} \mathrm{Ti}_{4} \mathrm{O}_{15}$ ceramics obtained by the pellet-laminated process (process III) also exhibited a well saturated hysteresis loop as shown in Fig. 12(b). The ferroelectric properties of the ceramics prepared by process III $\left(2 P_{\mathrm{r}}=13.5 \mu \mathrm{C} / \mathrm{cm}^{2}\right.$, $2 E_{\mathrm{c}}=52.3 \mathrm{kV} / \mathrm{cm}$ ) are superior to those of the specimens sintered by process II. The differences in the ferroelectric properties observed between these two processes are ascribed to the existence of pyrochlore phase which will reduce the spontaneous polarization and increase the coercive field. The above ferroelectric properties of

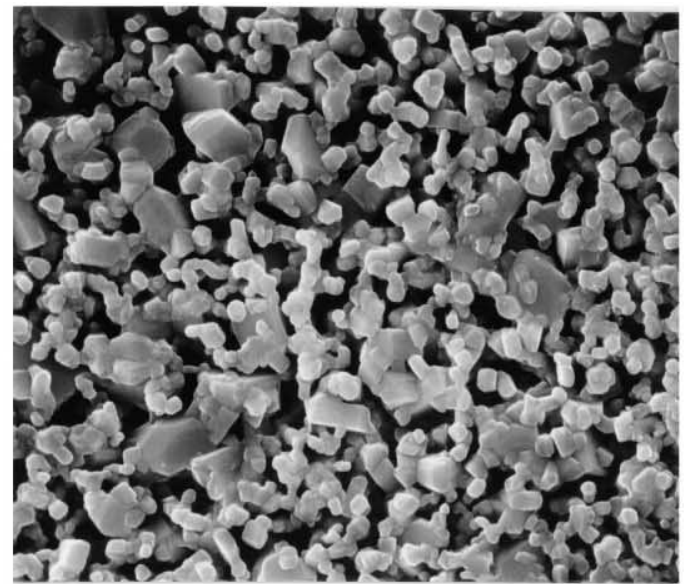

(a)
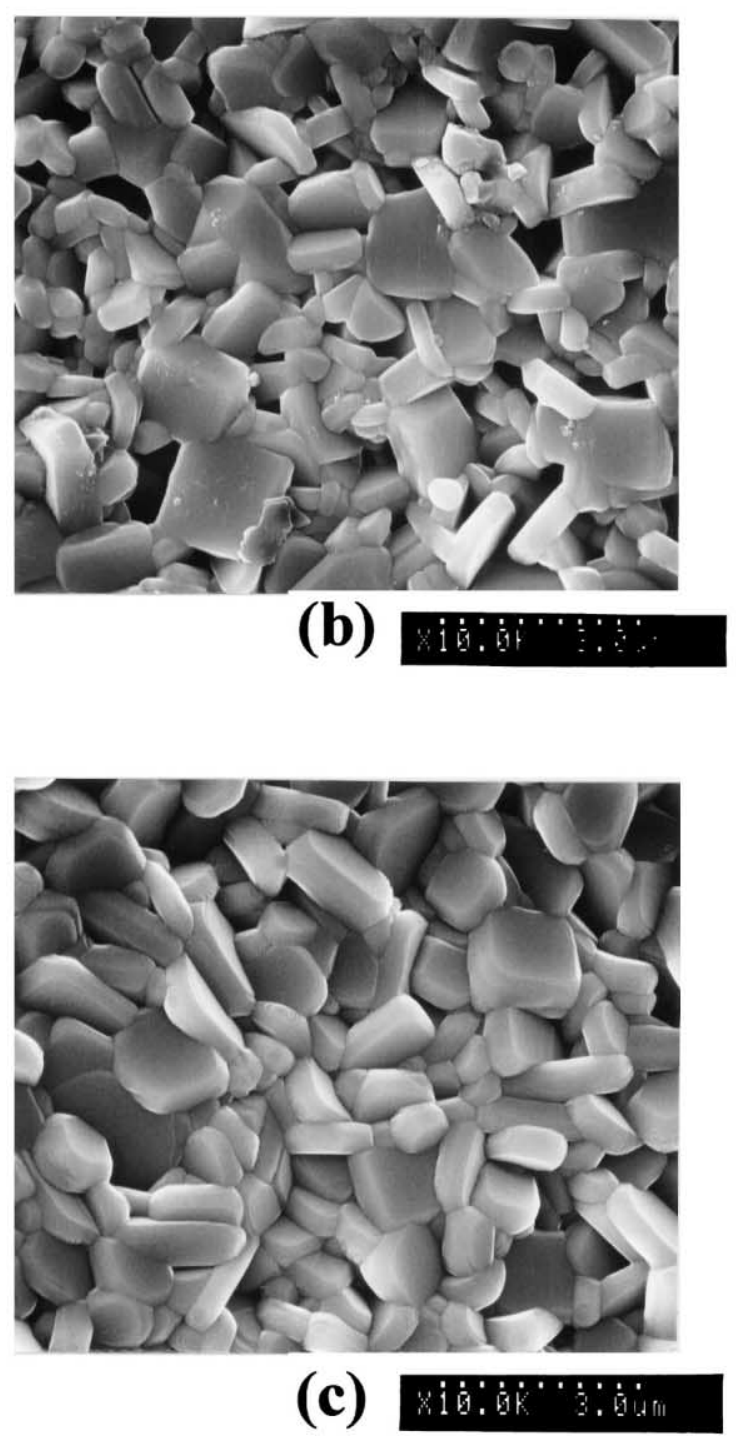

Fig. 11. Scanning electron micrographs of the $\mathrm{SrBi}_{4} \mathrm{Ti}_{4} \mathrm{O}_{15}$ ceramics sintered in process III at (a) $1100^{\circ} \mathrm{C}$, (b) $1150{ }^{\circ} \mathrm{C}$, and (c) $1200^{\circ} \mathrm{C}$ for $2 \mathrm{~h}$. 

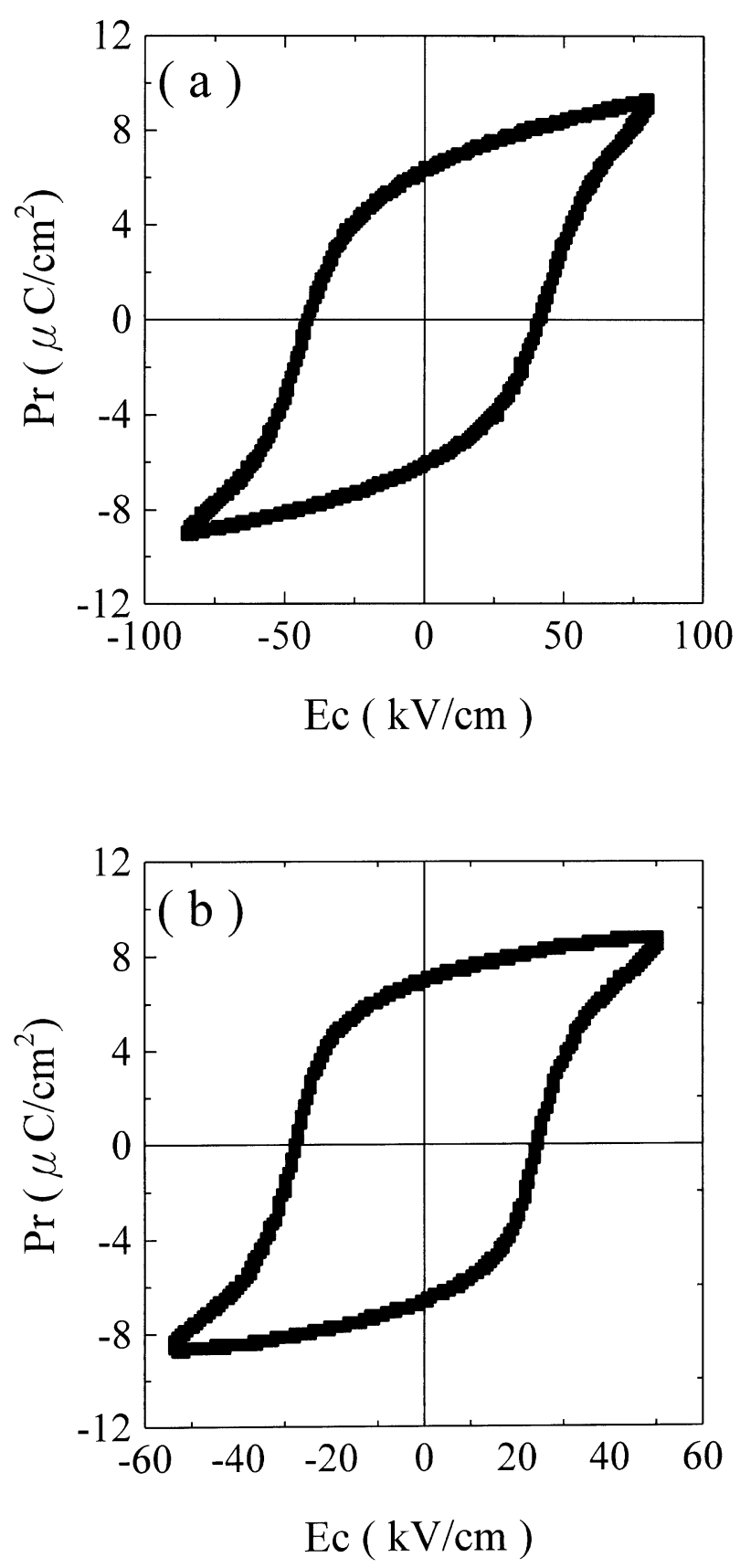

Fig. 12. P-E hysteresis loops of the $\mathrm{SrBi}_{4} \mathrm{Ti}_{4} \mathrm{O}_{15}$ ceramics sintered in (a) process II and (b) process III.

$\mathrm{SrBi}_{4} \mathrm{Ti}_{4} \mathrm{O}_{15}$ are better than those previously reported ${ }^{16}$ because the decomposition of $\mathrm{SrBi}_{4} \mathrm{Ti}_{4} \mathrm{O}_{15}$ at elevated temperatures was suppressed in this study. Moreover, the highly densified $\mathrm{SrBi}_{4} \mathrm{Ti}_{4} \mathrm{O}_{15}$ ceramics possess larger remnant polarization than $\mathrm{SrBi}_{2} \mathrm{Ta}_{2} \mathrm{O}_{9}$ ceramics. ${ }^{17}$ The densified $\mathrm{SrBi}_{4} \mathrm{Ti}_{4} \mathrm{O}_{15}$ ceramics obtained in this study not only offer more information on the intrinsic properties of bismuth-layer structured materials, but can also be applied to the PVD processes for preparing $\mathrm{SrBi}_{4} \mathrm{Ti}_{4} \mathrm{O}_{15}$ thin films.

\section{Conclusions}

The formation and sintering processes of $\mathrm{SrBi}_{4} \mathrm{Ti}_{4} \mathrm{O}_{15}$ were investigated in this study. $\mathrm{SrBi}_{4} \mathrm{Ti}_{4} \mathrm{O}_{15}$ started to form at $700{ }^{\circ} \mathrm{C}$ and the reaction was completed after calcination at $900^{\circ} \mathrm{C}$. $\mathrm{SrBi}_{4} \mathrm{Ti}_{4} \mathrm{O}_{15}$ ceramics could not be densified at low temperatures. Sintering at temperature higher than $1050{ }^{\circ} \mathrm{C}$ led to an increase in the density of $\mathrm{SrBi}_{4} \mathrm{Ti}_{4} \mathrm{O}_{15}$ ceramics; however, it also caused the decomposition reaction of $\mathrm{SrBi}_{4} \mathrm{Ti}_{4} \mathrm{O}_{15}$. The thermal decomposition of $\mathrm{SrBi}_{4} \mathrm{Ti}_{4} \mathrm{O}_{15}$ was attributed to the vaporization of bismuth species. Moreover, the diffusion of bismuth species caused the decomposition reaction to extend to the interior of ceramics. Highly densified $\mathrm{SrBi}_{4} \mathrm{Ti}_{4} \mathrm{O}_{15}$ ceramics with pure layered structure were obtained by the pellet-laminated process after sintering at $1200{ }^{\circ} \mathrm{C}$. Well-sintered $\mathrm{SrBi}_{4} \mathrm{Ti}_{4} \mathrm{O}_{15}$ ceramics exhibited relatively good ferroelectric properties compared with other layer-perovskite compounds. The remnant polarization $\left(2 P_{\mathrm{r}}\right)$ and coercive field $\left(2 E_{\mathrm{c}}\right)$ for the decomposition-free $\mathrm{SrBi}_{4} \mathrm{Ti}_{4} \mathrm{O}_{15}$ ceramics were 13.5 $\mu \mathrm{C} / \mathrm{cm}^{2}$ and $52.3 \mathrm{kV} / \mathrm{cm}$, respectively.

\section{References}

1. Scott, J. F. and Araujo, C. A., Ferroelectric memories. Science, 1989, 246, 1400-1405.

2. Chen, J., Harmer, M. P. and Smyth, D. M., Compositional control of ferroelectric fatique in perovskite ferroelectric ceramics and thin films. J. Appl. Phys., 1994, 76, 5394-5398.

3. Lee, J., Johnson, L., Safari, A., Ramesh, R., Sands, T. H. and Keramidas, V. G., Appl. Phys. Lett., 1993, 63, 27-29.

4. Jiang, Q., Subbarao, E. C. and Cross, L. E., Grain size dependence of electric fatigue behavior of hot pressed PLZT ferroelectric ceramics. Acta Metall., 1994, 42, 3687-3694.

5. White, G. S., Raynes, A. S., Vaudin, M. D. and Freiman, S. W., Fracture behavior of cyclically loaded PET. J. Am. Ceram. Soc., 1994, 77, 2603-2608.

6. Araujo, C. A., Cuchiaro, J. D., McMillan, L. D., Scott, M. C. and Scott, J. F., Fatigue-free ferroelectric capacitors with platinum electrodes. Nature, 1995, 374, 627-629.

7. Amanuma, K., Hase, T. and Miyasaka, Y., Preparation and ferroelectric properties of $\mathrm{SrBi}_{2} \mathrm{Ta}_{2} \mathrm{O}_{9}$ thin films. Appl. Phys. Lett. 1995, 66, 221-223.

8. Taylor, D. J., Jones, R. E., Zurcher, P., Chu, P., Lii, Y. T., Jiang, B. and Gillespie, S. J., Electrical properties of $\mathrm{SrBi}_{2} \mathrm{Ta}_{2} \mathrm{O}_{9}$ thin films and their temperature dependence for ferroelectric nonvolatile memory applications. Appl. Phys. Lett., 1996, 68, 2300-2302.

9. Aurivillius, B., Mixed bismuth oxides with layer lattices, I. The structure type of $\mathrm{CaNb}_{2} \mathrm{Bi}_{2} \mathrm{O}_{9}$. Arkiv for kemi, 1949, 1, 463-480.

10. Aurivillius, B., Mixed bismuth oxides with layer lattices, II. Structure of $\mathrm{Bi}_{4} \mathrm{Ti}_{3} \mathrm{O}_{12}$. Arkiv for kemi, 1950, 1, 499-512.

11. Aurivillius, B., Mixed bismuth oxides with layer lattices, III. Structure of $\mathrm{BaBi}_{4} \mathrm{Ti}_{4} \mathrm{O}_{15}$. Arkiv for kemi, 1950, 2, 519-527.

12. Watanabe, H., Mihara, T., Yoshimori, H. and Araujo, C. A., Preparation of ferroelectric thin films of bismuth layer structured compounds. Jpn. J. Appl. Phys., 1995, 34, 5240-5244.

13. Guo, C. L. and Wu, Y. Q., X-ray powder diffraction study of mixed bismuth oxide ferroelectrics with layer type structure. Lead bismuth titanate $\left(\mathrm{PbBi}_{4} \mathrm{Ti}_{4} \mathrm{O}_{15}\right)$ and strontium bismuth titanate $\left(\mathrm{SrBi}_{4} \mathrm{Ti}_{4} \mathrm{O}_{15}\right)$. Acta Phys. Sinica, 1980, 29, 1490-1496. 
14. Nibou, L., Aftati, A., El Farissi, M. and Mercurio, J. P., Chemical fabrication $\mathrm{SrBi}_{4} \mathrm{Ti}_{4} \mathrm{O}_{15}$ thin films. J. Eur. Ceram. Soc., 1999, 19, 1383-1386.

15. Lu, C. H. and Chen, Y. C., Sintering and decomposition of ferroelectric layered perovskites: strontium bismuth tantalate ceramics. J. Eur. Ceram. Soc., 1999, 19, 2909-2915.
16. Gelfuso, M. V., Thomazini, D. and Eiras, J. A., Synthesis and structural, ferroelectric, and piezoelectric properties of $\mathrm{SrBi}_{4}$ $\mathrm{Ti}_{4} \mathrm{O}_{15}$ ceramics. J. Am. Ceram. Soc., 1999, 82, 2368-2372.

17. Chen, Y. C. and Lu, C., H, Influence of the addition of bismuth oxide on the ferroelectric properties of layered strontium bismuth tantalate ceramics. Intergr. Ferroelectr., 1999, 26, 65-73. 